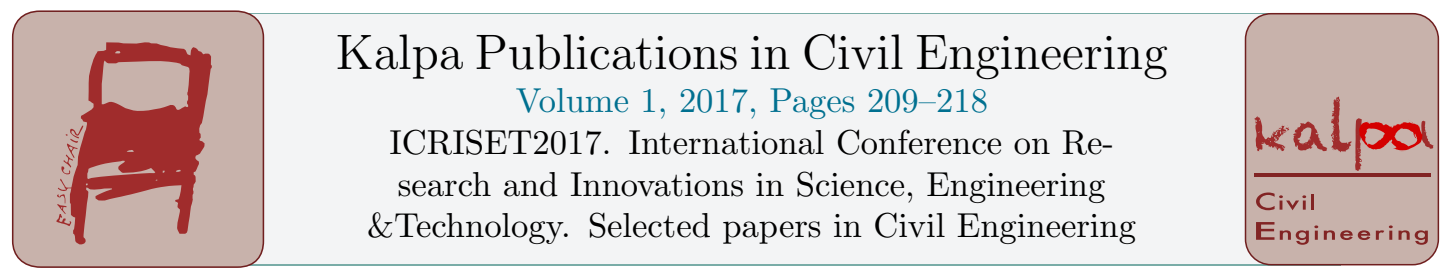

\title{
Capacities and LOS Measures of Intersections
}

Saiyad Shabazahara Mukhtyarali ${ }^{1}$, Dr. L.B. Zala ${ }^{2}$, Prof. Amit A Amin ${ }^{3}$

Transportation system Engineering

Birla Vishvakarma Mahavidyalaya

Vallabh Vidyanagar,Anand.

\begin{abstract}
Urbanization and industrialization has caused a drastic revolution all over the world. Intersections are crucial to street's performance. They control a speed, safety, cost, and efficiency, making right turns the key design factor in intersections improvements and operations. In Anand city of Gujarat state, due to increasing population growth and increased traffic need Capacity Evaluation selected intersections. Borsad Chowkdi-which is highly congestible, and similarly Ganesh Chowkdi and Janta Chowkdi with similar traffic conditions has been selected. Using two methods e.g.IRC-65 Method and HCM-2000 method Capacity of two Roundabouts and One un-signalized intersection has been evaluated. IRC-65(1976) method based on the geometrics of Rounabouts and give the Capacity of entire Intersections. HCM-2000 method, Design parameters are Critical Gap and Follow up Time based on Gap Acceptance Method, give the each leg Capacity.
\end{abstract}

Keywords- Roundabout, Intersection, Capacity ,Critical Gap,Gap Acceptance ,Follow up time

\section{INTRODUCTION}

In $1950,30 \%$ of world population lived in an urban area. In $2000,47 \%$ of world population lived in an urban area. At present, $54.4 \%$ population lives in urban area. These will increase up to $60 \%$ in year 2030.The urbanization due to rapid industrial growth and hence population density increased in cities. The population of Anand city and out Anand district are 198282 and 209410 respectively as per census 2011. In Anand there is one big GIDC approximately 200 industries at present. Anand - VallabhVidyanagar is an education hub. The Traffic Growth rate is $7.5 \%$ in Anand city. Traffic congestion is a condition on road networks that occurs due to increased road. It is characterized by slower speed, longer trip time and increased vehicular queuing. When traffic demand is high and interaction between vehicles increase reducing the speed of the traffic stream, this result in congestion. Intersection is an area shared by two or more roads. This area is designated for the vehicles to turn to different directions to reach their desired destinations. Its main function is to guide vehicles to their respective directions. Traffic intersections are complex location because vehicles moving in different direction to occupy same space at the same time. In addition, the pedestrians also seek same space for crossing. Drivers have to make split second decision at an intersection by considering his route, intersection geometry, speed and direction of other vehicles etc. A small error in judgment can cause severe accidents. Therefore, both from the accident perspective and the capacity perspective, the study of intersections important for the traffic engineers especially in the case of urban scenario. 
Due to biased attention of driver, fast riding attitude of students, improper geometry of roads and intersections, problems related to congestion and safety needs intersections improvements study. Gowri Asaithambi and Chepuru Anuroop studied in June 2016 and established a relationship between occupation time and critical gap. They concluded as increase in ooccupation time critical gap also increases [2]. Liang ren, XiaoboQu, Hong Guan, Said Easa did comparative studies of different methods i.e. HCM-2000, HCM-2010, (NRC) New Roundabout Capacity, German Highway Capacity Manual (GHCM) etc. They concluded that in low and medium traffic volume each method estimate a similar capacity varying in small range[8]. Haiyuan Li, ZongTian, and Wei Deng established a model which provides an improved method over HCM-2000 and VISSIM simulation for estimating capacity of vehicular movements at multilane Two Way Stop Control (TWSC) intersections with various lane configuration and traffic demand [3].

In this paper, methods used for performance evaluation are (1) HCM-2000 (2) IRC-65 (1976) for uncontrolled and semi-controlled intersections. IRC method is based on the road geometric data which can be taken by road Inventory survey and result a weaving section capacity. In HCM method main parameters are Critical gap and Follow up time based on Gap Acceptance Model. Werner Brilon, and Ning Wu illustrated the analytical background of the procedures and as well as correct use of various parameters and represented use of graphical method in field[17].Rui-junGuo and Bo-Liang Lin were concluded that the exponential model of rejected proportion is more often practical than the linear model, and typical capacity functions were improved by using the accepted proportion function[15].

The main problem arise in calculating base critical gap and follow up time. Harsh Jigishbhai Amin, Akhileshkumar Maurya provided detailed review of study related to estimation of critical gap. They Raff method, Greenshield method, The lag method, Harder's method, Acceptance curve method, Logit method, Ashworth's method, Wu'smodeland and clearing behaviour approach methods are really failing to represent a realistic value of the critical gap at four legged median separated uncontrolled intersection in Ahmedabad[5]. For the conversion of heterogeneous traffic into homogeneity for correct calculation of capacity Mathew Sonu, AshishDhamaniya, ShriniwasArkatkar, and Gaurang Joshi gave new PCU value for four legged roundabouts[11].The common PCU values adopted for various classes of vehicles for different movements are given in Table 1.

Table 1 PCU values adopted for various classes of vehicle

\begin{tabular}{|c|c|c|c|}
\hline Classes of vehicles & Left Turn Movement & Straight Movement & Right Turn Movement \\
\hline 2 Wheeler & 0.22 & 0.22 & 0.22 \\
\hline 3 Wheeler & 0.67 & 0.67 & 0.67 \\
\hline 4 Wheeler & 1.26 & 1.29 & 1.32 \\
\hline Bus/Truck & 4.04 & 4.43 & 4.64 \\
\hline
\end{tabular}

Source: Reference[12] 


\section{SITE SELECTION}

For performance evaluation of Janta Intersection: At Janta Intersection the State Highway- 83 and road from VallabhVidyanagar and road coming fromVithalUdyognagar Industrial area (VUIAI)are meets. It is a semicontrolled Rotary Intersection.

Borsad Intersection: This is a highly congestedintersection in Anand city. There are two main roads; state highway -83 and Major road - 228 of Anandcity intersect. It consists a high flow of traffic yet it is uncontrolled interesection at present.

Ganesh Intersection: At ganesh intersection State highway-83 which carry major flow coming from national highway- 8 meets. The road coming from Amul dairy to Mangalpura area at Ganesh chowkdi. It is a semi controlled intersection with rotary.

The location are shown in Figure 1 below.

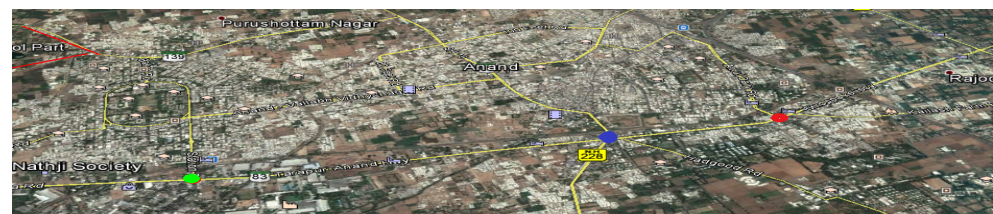

Figure 1 Locations of Intersections

\section{DATA COLLECTION}

It is extremely important to study different traffic movements in all possible directions at entry and exit points of approaches and in Roundabout along with its circulatory traffic movements. For that at two typical roundabouts having a $16 \mathrm{~m}$ and $20 \mathrm{~m}$ diameter of Ganesh and Janta intersection respectively considered in this study. Third intersection is uncontrolled Two Way Stop Control (TWSC) intersection e.g. Borsad Intersection.

The all approach roads are four lane divided in all directions. Various important Data aggregated on a weekday during off peak hours and peak hours on the selected intersections using high resolution camera mounted on the top of the nereby building.Inventory survey was carried out for geometrics data of road approaches and roundabouts i.e. width of roadway, footpath, carriage way, and also for roundabouts i.e. the diameter of central island, entry and exit width and, weaving length, weaving width as shown in table 2 .

Table 2Inventary details of different Intersectios

\begin{tabular}{|c|c|c|c|c|}
\hline & JantaInt. & Ganesh Int. & \multicolumn{2}{|c|}{ Borsad Intersection } \\
\hline EntryWidth & 4 & 4 & Right of way & 28.5 \\
\hline Exit Width & 4 & 4 & Footpath (left) & 6 \\
\hline WeavingLength & 15 & 12 & FootPath (Right) & 6 \\
\hline $\begin{array}{c}\text { Cental Island } \\
\text { Diameter }\end{array}$ & 18 & 15 & Carriage way & 16.5 \\
\hline
\end{tabular}

Source: Inventory detail at site (all dimensions are in meter) 
Classified traffic volume count carried out for determining the proportion heavy vehicles and turning movements. Traffic flow converted into a stream of PCU using Equivalency factor on the bases of value given in table 1. Circulating flow for Roundabouts is calculated as

Circulatory Flow $(\mathrm{N})=($ straight turning movement from $\mathrm{W})+($ Right turming movement from $\mathrm{W})+($ Right Turning from S)

Critical Gap is defined as minimum gap between the major street vehicles that allows the intersection entry of one minor street vehicle. Follow up time is defined as the time between departure of first vehicle from the minor stream at the same time departure of next vehicle using same gap from the major stream. Critical gap estimated using a probability of gap acceptance and gap rejection. The accepted and rejected gap can be surveyed using programme developed by Dr. P J. Gundaliya used for headway calculations. Situation when vehicles are arrived in a random manner, the headway between vehicles are exponentially distributed. The proportion of time occupied by interval i.e. minimum acceptable Gap.

The probability of gap acceptance and gap rejection related to the Arrival rate computed using relation (1). The results are present in figure 2.

$$
\mathbf{P}_{\mathbf{t}}=\mathbf{e}^{-\boldsymbol{\mu t}}(\boldsymbol{\mu t}+\mathbf{1}) \quad(1) \boldsymbol{\mu}=\operatorname{Arrival} \text { rate of } \operatorname{vehicle}\left(\frac{\mathrm{veh}}{\mathrm{hr}}\right)
$$

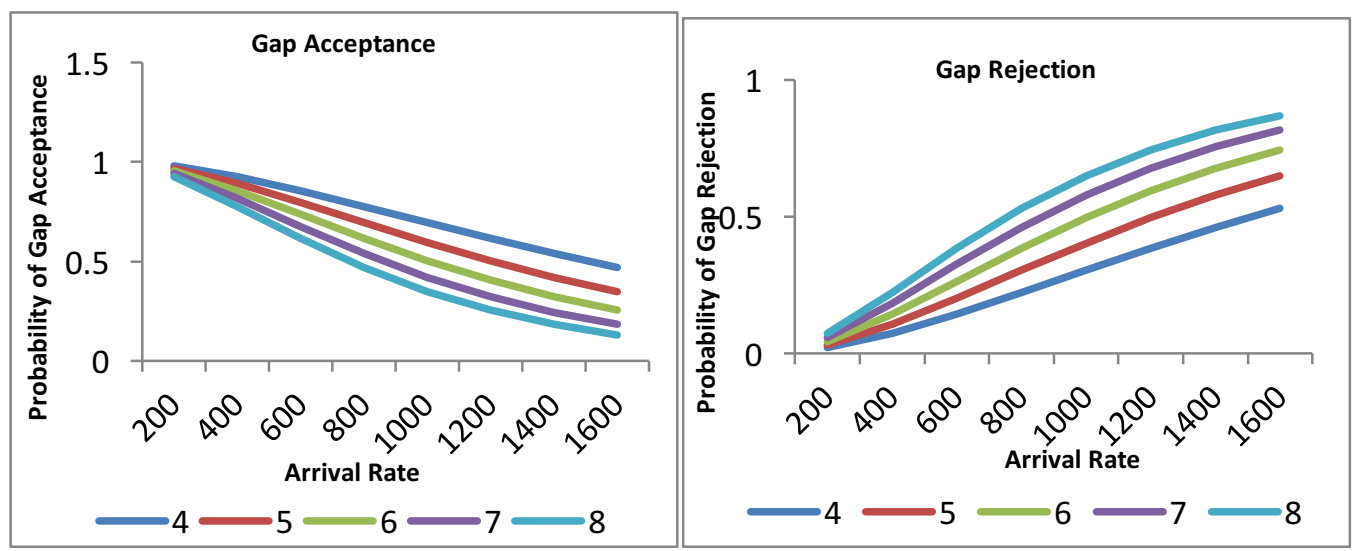

Figure 2 Probability of gap Acceptance and gap Rejection

Based on the Gap Acceptance and Rejection probability approach the critical gap taken into consideration as table 4 for roundabouts. The follow up time estimates manually from vediography as explained earlier in this paper. 
Table 3 Critical gap and Follow up time for Roundabouts (col. 1,2,3) TWSC (col. 4,5,6)

\begin{tabular}{|c|c|c|c|c|c|}
\hline & CG & FT & Turning movements & Base CG & Base FT \\
\hline NB & 1.6 & 1.2 & RT from E\&W & 1.64 & 1.32 \\
\hline SB & 1.7 & 1.3 & LT from N\&S & 2.48 & 1.98 \\
\hline EB & 1.6 & 1.2 & TH on N\&S & 2.60 & 2.4 \\
\hline WB & 1.7 & 1.3 & RT from N\&S & 2.84 & 1.4 \\
\hline
\end{tabular}

Source: Based on collected headway at site

N-North, S-South, E-East, W-West CG-Critical Gap FT- Follow up Time

The estimation of critical gap and follow up time for TWSC intersection using Equation(2). In that, base critical gap and follow up time selected on the basis of Probability approach as given above. The base critical gap for TWSC intersection as table 5 .

Using this base values tha Critical gap and Follow up time can be calculated using Equation (2) and (3) respectively.

$t_{c, x}=t_{c, \text { base }}+t_{c, x}=t_{c, \text { base }}+t_{c, H V} * P_{H V}+t_{c, G} * G-t_{c, T}-t_{3, L T}$

$\mathrm{t}_{\mathrm{c}, \mathrm{x}}=$ critical gap for movement $\mathrm{xt}_{\mathrm{c} \text {,base }}=$ base critical gap, (s)

$t_{c, G}=$ adjustment factor for grade $G=$ percent grade divided by 100

$\mathrm{t}_{\mathrm{c}, \mathrm{T}}=$ adjustment factor for each part of two stage gap acceptance process

$\mathrm{t}_{3, \mathrm{LT}}=$ adjustment factor for intersection geometry

$\mathrm{t}_{\mathrm{f}, \mathrm{X}}=\mathrm{t}_{\mathrm{f}, \text { base }}+\mathrm{t}_{\mathrm{f}, \mathrm{HV}} * \mathrm{P}_{\mathrm{HV}}$

\section{CAPACITY DETERMINATION}

Capacity of roundabouts are calculatedusing two different methods i.e. HCM-2000 and IRC65. In HCM-2000 capacity is calculated using Equation(4).

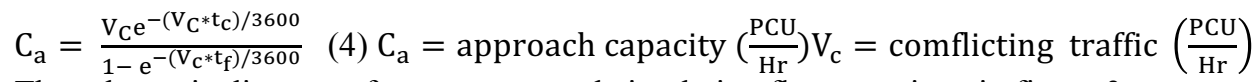
The schematic diagram of movements and circulating flow are given in figure 3 .

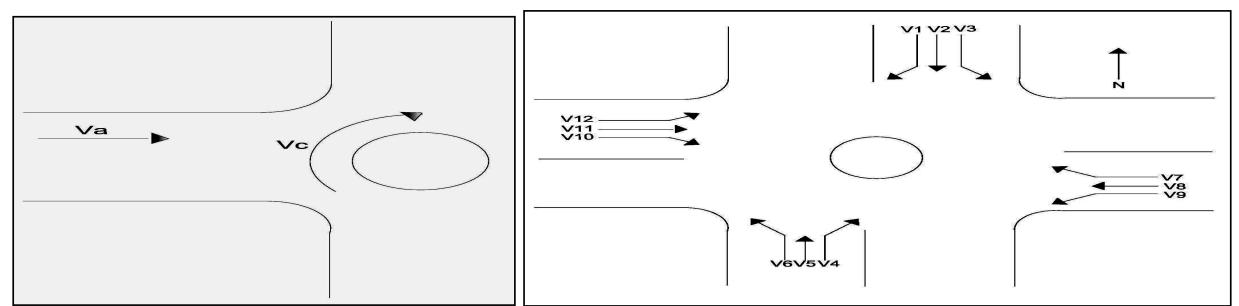

Figure 3Circulating flow for roundabout and site movements

The Equation for estimating Capacity using IRC-65 
$\mathrm{w}=$ width of weaving section in $\mathrm{mt} \quad \mathrm{e}=$ average entry width of the rotary in $\mathrm{m}$

$$
\mathrm{w}=\frac{\mathrm{e}_{1}+\mathrm{e}_{2}}{2}+3.5 \mathrm{p}=\frac{\mathrm{b}+\mathrm{c}}{\mathrm{a}+\mathrm{b}+\mathrm{c}+\mathrm{d}}
$$

$p=$ proportion of weaving traffici.e. ratio of sum of crossing stream to the total traffic For the calculation of proportion of weaving traffic assign the movements as figure 4.

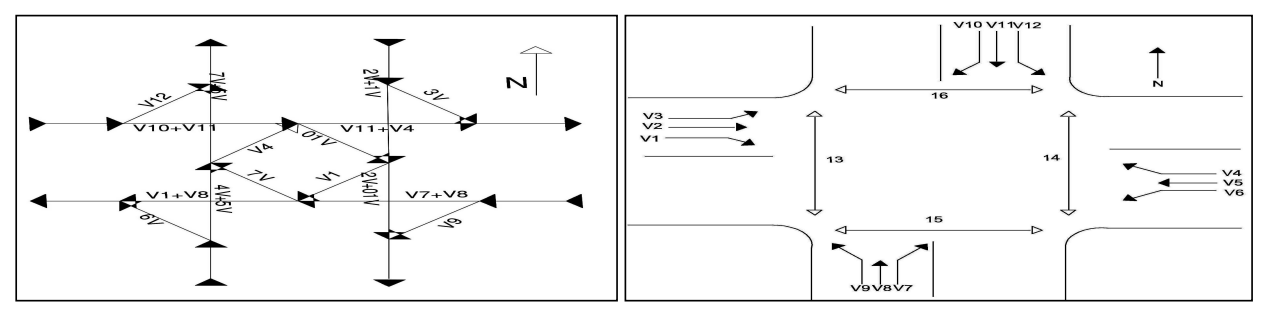

Figure 4Assign way\& Site movements for TWSC intersections

The movements of traffic at TWSC is shown in figure 6.

The Gap Acceptance model used in this method computes the potential capacity of each minor traffic stream in accordance with Equation(6).

$C_{p, x}=V_{c, x} \frac{e^{-\left(\frac{V_{c} * t_{c, x}}{3600}\right)}}{1-e^{-\left(\frac{V_{c} * f_{f}}{3600}\right)}}(6) C_{p, x}=$ potential capacity movement $\mathrm{xV}_{c, x}=$ conflicting flow rate

The Potential capacity assuming the following Base condition.

1. Traffic from nereby intersections does not back up into subject intersection.

2. A separate lane is provided for each minor street movement.

3. Upstream signal does not affect the arrival pattern.

4. No other movement of Rank 2, 3, 4 does not affect subject movement.

The conflicting flows are calculated as given figure 6 .

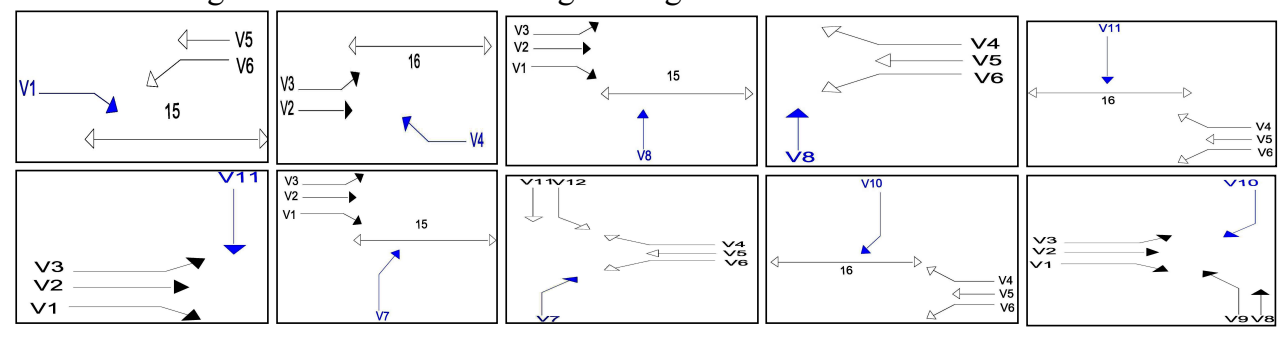

Figure 6 Conflicting flows for TWSC intersection

Two stage gap acceptance procedure, the intersection is considered in two parts. Between the partial intersections there is a storage space for $\mathrm{m}$ vehicles and this area has to be passed by the right turn vehicles. It causes the two stage of the movements, as shown above. Through movements 8,11 and right turn movements 7,10 having two stage. 
Movement capacity is capacity in accordance with pedestrian impedance, traffic flow impedance on the priority bases. The priority of movements are given as ranks.

1. Rank 1: Through traffic from major street and left turning traffic from major street. Movements are: $2,5,3,6,15,16$

2. Rank 2: Right turning traffic from major street and left turning traffic into the major street. Movements are: $1,4,9,12,13,14$

3. Rank 3: Through traffic on the minor street. Movements are: 8,11

4. Rank 4: Right turning traffic from minor street. Movements are: 7,10

The movement capacity for rank 1 and Rank 2 Movements are same as a PotentialCapacity. For rank 3 and 4 it is impeded by pedestrian movements. The movement capacity for rank 3 and 4 is based on the probability of queue free state and pedestrian impedance.

The probability of queue free state is found using Equation(7).

$$
\mathrm{P}_{0, \mathrm{j}}=1-\frac{\mathrm{v}_{\mathrm{j}}}{\mathrm{C}_{\mathrm{m}, \mathrm{J}}}
$$

$\mathrm{C}_{\mathrm{m}, \mathrm{j}}=$ movement capacity for $\mathrm{j}$ movement $\quad \mathrm{V}_{\mathrm{j}}=$ traffic flow of RT of rank 2

$\mathrm{P}_{0, j}=$ probability that conflicting rank $2 \mathrm{mvmt} \mathrm{j}$ will operate on queue free state

$\mathrm{C}_{\mathrm{m}, \mathrm{x}}=\mathrm{P}_{0, \mathrm{j}} * \mathrm{C}_{\mathrm{p}, \mathrm{x}}$

The pedestrian impedance is obtained using Equation(9) and (10) below

$f_{p b}=\frac{v_{x} * \frac{w}{S_{P}}}{3600}(9) f_{p b}=$ pedestrian blockage factor $\quad V_{x}=$ number of pedestrian

$\mathrm{w}=$ lane width $(\mathrm{m}) \mathrm{S}_{\mathrm{p}}=$ pedestrain walking speed $\left(1.2 \frac{\mathrm{m}}{\mathrm{s}}\right) \mathrm{P}_{\mathrm{p}, \mathrm{x}}=1-\mathrm{f}_{\mathrm{pb}}$

$\mathrm{P}_{\mathrm{p}, \mathrm{x}}=$ pedestrian impedance factor $\mathrm{P}_{\mathrm{p}, \mathrm{x}}=$ pedestrian impedance factor

$\mathrm{P}_{\mathrm{p}, \mathrm{x}}=1-\mathrm{f}_{\mathrm{pb}}(10)$

For evaluation of level of service control delay is estimated using Equation(11).

Total delay is the difference between the travel time actually experienced and the reference travel time that would result during base conditions.

$\mathrm{d}=\frac{3600}{\mathrm{C}_{\mathrm{m}, \mathrm{x}}}+900 \mathrm{~T}\left(\frac{\mathrm{V}_{\mathrm{x}}}{\mathrm{C}_{\mathrm{mx}}}-1+\sqrt[2]{\left(\frac{\mathrm{V}_{\mathrm{x}}}{\mathrm{C}_{\mathrm{mx}}}-1\right)^{2}+\frac{\frac{3600}{C_{\mathrm{mx}} * \frac{\mathrm{V}_{\mathrm{x}}}{C_{\mathrm{mx}}}}}{450 \mathrm{~T}}}\right)+5$

$\mathrm{V}_{\mathrm{x}}=$ flow rate for movement $\mathrm{x} \cdot \mathrm{d}=$ control delay

$\mathrm{C}_{\mathrm{m}, \mathrm{x}}=$ capacity of movement $\mathrm{x} \quad \mathrm{T}=$ analysis time period 0.25 for 15 minute

The level of service criteria mentioned as Table 4 . 
Table 4LOS criteria based on delay

\begin{tabular}{|c|c|}
\hline Level of service & Average controldelay(s/veh) \\
\hline A & $0-10$ \\
\hline B & $>10-15$ \\
\hline C & $>15-25$ \\
\hline D & $>25-35$ \\
\hline E & $>35-50$ \\
\hline F & $>50$ \\
\hline
\end{tabular}

Source: HCM-2000

\section{RESULTS}

1. The capacity of roundabouts obtained using HCM-2000 and IRC-65 methods are tabulated in Table 5 and 6.

Table 5 Capacity $\&$ v/c ratio of intersection

\begin{tabular}{|c|c|c|c|c|c|c|}
\hline & \multicolumn{4}{|c|}{ HCM-2000 } & \multirow[t]{2}{*}{ IRC-65 } \\
\hline & & NB & SB & EB & WB & \\
\hline \multirow{2}{*}{$\begin{array}{c}\text { JANTA } \\
\text { INTERSECTION }\end{array}$} & $\mathrm{C}$ & 1919 & 2064 & 2478 & 2320 & 1287 \\
\hline & $\mathrm{v} / \mathrm{c}$ & 0.36 & 0.17 & 0.37 & 0.78 & 1.42 \\
\hline \multirow{2}{*}{$\begin{array}{c}\text { GANESH } \\
\text { INTERSECTION }\end{array}$} & $\mathrm{C}$ & 2446 & 1735 & 2308 & 2234 & 1327 \\
\hline & $\mathrm{v} / \mathrm{c}$ & 0.47 & 0.11 & 0.44 & 0.43 & 0.86 \\
\hline
\end{tabular}

2. The delay of TWSC is given in Table6.

Table 6 Average controlled delay at TWSC (Borsad Intersection)

\begin{tabular}{|l|l|l|l|l|l|l|l|}
\hline Movements & 8 & 11 & 7 & 10 & 1 & 4 & 9 \\
\hline Delay (s) & 21 & 35 & 48 & 45 & 25 & 15 & 23 \\
\hline LOS & $\mathrm{C}$ & $\mathrm{D}$ & $\mathrm{E}$ & $\mathrm{E}$ & $\mathrm{D}$ & $\mathrm{C}$ & $\mathrm{C}$ \\
\hline
\end{tabular}

VI. CONCLUSIONS

1. The low v/c ratio at Ganesh and Janta intersections indicated that the intersections are performing well. The total delay and corresponding LOS indicates that performance of intersection is low and needs immediate planning and improvement.

2. The IRC-65 methods over estimates v/c ratio compared to HCM-2000, this shows revision need in IRC-65. 


\section{References}

[1] AvijitMaji, AkhileshkumarMaurya, Suresh Nama, Prasanta K. Sahu, (2015), "Performance based analysis intersection layout under a flyover for heterogeneous traffic", Journal of Modern Transport.

[2] C. S. Popacostas,P. D. Prevedouros, (2004) “Transportation Engineering and Planning” $3^{\text {rd }}$ Edition.

[3] GowriAsaithambi, ChepuruAnuroop, (june 2016), "Analysis of Occupation time of vehicles at Urban Unsignalized Intersections in Non-lane Based Mixed Traffic Conditions", Journal of Modern Transport.

[4] Haiyuan Li, ZongTian, and Wei Deng, (2011), " Capacity of TWSC Intersection for Multilane Approach", $6^{\text {th }}$ International Symposium on Highway capacity and Quality of Service Stockholm, Sweden June 28 - July 1,2011.

[5] HarshJigishbhai Amin, AkhileshkumarMaurya,(2015), “ A review of critical gap estimation approaches at uncontrolled intersection in case of heterogeneous traffic conditions", The Journal of Transport Literature, India.

[6] Highway Capacity Manual - 2000. Transportation Research Board, Washington D. C., 2000.

[7] Hiren Patel, (2015), "Conversion of Grade Signalized Intersection in to Grade Separated Intersection", International Journal of Innovative research in Science and Technology, Volume 2, Ahmadabad.

[8] IRC-65 (1976) "Recommended practice for Traffic Rotaries", Indian Road Congress, New Delhi.

[9] Liang ren, XiaoboQu, Hong Guan, Said Easa, M.ASCE, and Erwin Oh, (2016), "Evaluation of Roundabout Capacity Model: An Empirical Case Study", American Society of Civil Engineering, USA.

[10] Mahesh S. Aparaj, M. N. Shiv kumar, “ Benefit Cost Analysis of Grade Separated Interchange At a S.S. Circle Tamkur - A Case Study", Transportation Engineerimg and Management, SIT Tunker.

[11] Martin Wohl and Brian V Martin, "Traffic System Analysis for Engineers and Planners", Mcgrow-Hill Book Company.

[12] Mathew Sonu, AshishDhamaniya, ShriniwasArkatkar, and Gaurang Joshi, (2016),"Time Occupancy as Measure of PCU at four Legged Roundabouts", The International Journal of Transportation Reaserch.

[13] Michael P. Dixon, Ahmed Abdel-Rahim, Michael Kyte, Phil Rust, Howard Cooley, and Lee Rodegerdts, (2007), "Field Evaluation of Roundabout Turning Movement Estimation Procedures", American Society of Civil Engineers.

[14] NavneetMonga, AnoopBishnoi, (2015), "Basic Design Parameters for an Intersection \& Design Criteria for Unsignalized Intersections on NH-10, Sirsa", International Journal on Emerging Technologies 6(2). 
[15] RamuArroju, Hari Krishna Gaddam, LaxmideviVanumu, K. RamchandraRao, (2015),"Comaparative evaluation of roundabout capacities under heterogeneous traffic condition", Journal of Modern Transport.

[16]Rui-junGuo and Bo-Liang Lin, (2011), "Gap Acceptance at Priority-Controlled Intersections", American Society of Civil Engineers.

[17] S. K. Mahajan, AnshulUmadekar, KrutiJethva, (2013), "New Concept of Treaffic Rotary Design at Road Intersections", International Conference of Transportation Professionals.

[18] Werner Brilon, and Ning Wu (2003), "Two Stage Gap Acceptance- Some Classification", National Research Council, Washington D.C., USA. 